\title{
Possible Use of Sepiolite as Alternative Filler for Natural Rubber
}

\author{
Abdulhakim Masa ${ }^{(\mathbb{D})}$, Awatif Krem-ae ${ }^{b}$, Hanafi Ismail , Nabil Hayeemasa $^{b *}$ (1) \\ ${ }^{a}$ Prince of Songkla University, Sino-Thai International Rubber College, Hat Yai, Songkhla, 90110 \\ Thailand. \\ ${ }^{b}$ Prince of Songkla University, Faculty of Science and Technology, Department of Rubber Technology \\ and Polymer Science, Pattani Campus, 94000, Pattani, Thailand. \\ ${ }^{c}$ Universiti Sains Malaysia, School of Materials and Mineral Resources Engineering, Engineering \\ Campus, 14300, Nibong Tebal, Penang, Malaysia.
}

Received: March 13, 2020; Revised: July 21, 2020; Accepted: August 14, 2020

\begin{abstract}
The use of mineral fillers in rubber industry has been increasingly focused. Sepiolite is considered as one of the mineral fillers that exploits unique characteristics. This is due to its unique needle-like fibrous and a tunnel-like micro-pore channel structures. Therefore, adding this filler in natural rubber (NR) matrix would bring tremendous advantage. The study was carried out in the form of curing characteristics, tensile properties and morphology together with the dynamic properties. Filling sepiolite to NR has brought to a noticeable enhancement of curing characteristics, tensile properties and morphology. This is contributed to the distinctive structure of sepiolite itself, it provides a better dispersion to the NR. Surface roughness of the composites is visibly found which is responsible for the mechanical properties. Further verification was also monitored through the dynamic properties of the composites. The obtained profiles are in good agreement to the tensile properties and morphological characteristics observed.
\end{abstract}

Keywords: Natural Rubber, Sepiolite, Mineral Filler, Tensile Properties, Dynamic Property.

\section{Introduction}

In manufacturing rubber products, it cannot be denied that filler has become the main ingredient after the rubber matrix. Filler has been incorporated to rubber to encounter many purposes, e.g., to improve the mechanical performance, service life and even to cheapen the manufacturing $\operatorname{cost}^{1}$. Filler is classified based on its own performance; the reinforcing filler is recommended when high strength is essential. However, non-reinforcing filler is needed when the cost is mainly concerned ${ }^{2}$. Recently, there is a number of fillers used in compounding rubber composites ${ }^{3-5}$. The most common fillers used in rubber industries are conventional carbon black and silica. However, high energy consumption is usually required for production of these fillers. Thus, searching other alternative fillers is of great interest and various possibilities for combining rubber and filler remains largely unexplored.

Considering the filler from clay family, sepiolite is another example, having special characteristics as compared to other types of fillers ${ }^{6}$. Figure 1 illustrates the morphology and chemical structure of sepiolite. The microfibrous morphology of sepiolite is in the form of microcrystalline hydrated magnesium silicate with the chemical formula of $\left.\mathrm{Si}_{12} \mathrm{Mg}_{8} \mathrm{O}_{30}(\mathrm{OH}, \mathrm{F})_{4}\right] \cdot\left(\mathrm{H}_{2} \mathrm{O}\right)_{4} \cdot 8 \mathrm{H}_{2} \mathrm{O}^{7,8}$ and length of the fibrous sepiolite is ranged from $2-10 \mu \mathrm{m}$. Sepiolite also has unique needle structure consisting of tunnel-like micropore channel. Such tunnel-like channels are in an order of layers that arrange towards the fibrous direction ${ }^{9}$. A central

*e-mail: nabil.h@psu.ac.th sheet of magnesium oxide-hydroxide is sandwiched by the layer of two tetrahedral siloxane sheets. This interesting characteristics of sepiolite have brought to provide efficient adsorption and high surface area. As a consequence, preparing the new composites based on the sepiolite and natural rubber is challenging and worth to explore.

Sepiolite was previously incorporated into NR without the use of sulfur in the compound ${ }^{10}$. It was mainly focused on the vulcanizing kinetics and tensile properties of the rubber. The resultant mechanical properties were not satisfactory due to compatibility concern. Recently, Hayeemasae et al. ${ }^{9}$ tried to enhance the compatibility between rubber matrix and sepiolite by replacing the NR with epoxidized natural rubber. (ENR). The composites were prepared on the laboratory sized two-roll mill. The overall properties were enhanced but a very low amount of sepiolite was used. The low shearing force obtained from the roll mixing might be the reason to limit the dispersion of sepiolite. Effects of sepiolite content and dispersion methods were also focused by Bhattacharya et al. ${ }^{11}$. They found that the dispersion of sepiolite was found to have enhanced on mixing the nanofibers but requiring a very low speed in the Brabender (20 rpm) for a longer period of time $(20 \mathrm{~min})$. This was attributed to the availability of more time and space for polymer diffusion and adsorption on to the nanofiller surface. Although they found out that their method of mixing was promising, but it might not be of great practical relevance when considering the time consumption. Nevertheless, the acting shear forces strongly favor the dispersion of filler and is a strong argument 


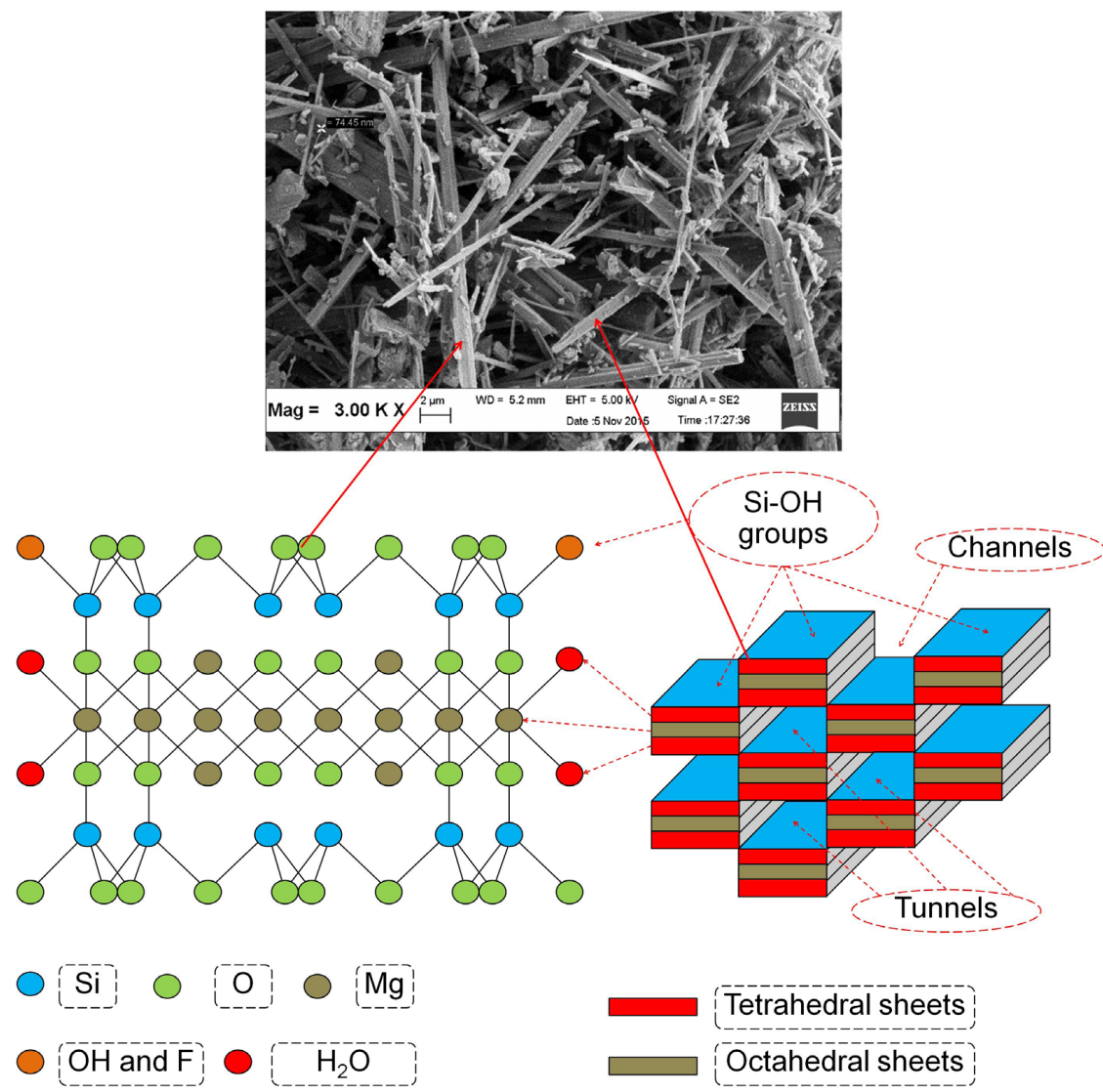

Figure 1. Sepiolite shape and structure.

for melt compounding with rubbers. Thus, searching for an alternative and effective approach for preparing the rubber composite is of great interest.

The idea of this present work is to propose the conventional mixing method to incorporate the sepiolite into the NR. Considering the unique shape in association with the unique controlled mixing condition, it is anticipated that high amount of sepiolite is possible to provide strong interaction between the sepiolite and rubber, giving the composite with higher mechanical properties. The solution presented in this work relates to the key benefits on manufacturing new products from alternative fillers with high performance and stability from sepiolite filled natural rubber composite. To some extent, sepiolite could also replace the addition of white fillers such as silica, clay and calcium carbonate without requiring the addition of silane coupling agent which is considered the complicated and costly methods. In this article, NR composites containing different sepiolite content were prepared. The studies were evaluated and decided based on certain properties such as curing characteristics, tensile properties and their corresponding rubber-filler interaction and micro-fractured surfaces.

\section{Experimental Details}

\subsection{Materials}

The formulation used to prepare the rubber composite is listed in Table 1. STR 5L grade of NR was manufactured
Table 1. The formulation used for compounding the sepiolite filled NR composites.

\begin{tabular}{cc}
\hline Material & Formulation (phr) \\
\hline STR 5L & 100 \\
\hline Steatic acid & 1 \\
\hline ZnO & 5 \\
\hline CBS & 1.5 \\
\hline Sulfur & 2.5 \\
\hline Sepiolite & $0,5,10,15 \& 20$
\end{tabular}

by Chalong Latex Industry Co., Ltd., Thailand. Sepiolite was mined and supplied by Hebei Dfl Minmet refractories Corporation, Shijiazhuang, Hebei, China and it was used as a received form. The composition of sepiolite is as follows; $53.5 \mathrm{wt} \%$ of $\mathrm{SiO}_{2}, 22.8 \mathrm{wt} \%$ of $\mathrm{MgO}, 1.93 \mathrm{wt} \%$ of $\mathrm{Al}_{2} \mathrm{O}_{3}$, 0.58 wt $\%$ of $\mathrm{Fe}_{2} \mathrm{O}_{3}, 0.51$ wt $\%$ of $\mathrm{K}_{2} \mathrm{O}, 0.17 \mathrm{wt} \%$ of $\mathrm{CaO}$ and other traces with the loss on ignition of $19.3 \%{ }^{8}$. The information on the physical properties of the sepiolite are shown in Table 2. Apart from the major ingredients used, the curing activator, $\mathrm{ZnO}$ and stearic acid were purchased from Imperial Chemical Co., Ltd., Bangkok, Thailand. ZnO and Global Chemical Co., Ltd., Samut Prakan, Thailand respectively. The curing accelerator which is N-cyclohexyl2-benzothiazole sulfenamide (CBS) was purchased from Flexsys America L.P., West Virginia, USA and finally the sulfur which was used as curing agent, was supplied by Siam Chemical Co., Ltd., Samut Prakan, Thailand. 
Table 2. Typical characteristics of sepiolite ${ }^{8}$.

\begin{tabular}{lc}
\hline \multicolumn{1}{c}{ Properties } & Outputs \\
\hline Colour & Light cream \\
\hline Form & Powder \\
\hline Size & 325 mesh or $44 \mu \mathrm{m}$ \\
\hline Bulk density & $0.86 \mathrm{~g} / \mathrm{ml}$ (Typically $600-1200 \mathrm{~kg} / \mathrm{m} 3)$ \\
\hline Expanded volume & $9-10 \mathrm{ml} / \mathrm{g}$ \\
\hline Impurity & $5-9 \%$ \\
\hline Moisture & $0.5-2 \%$ \\
\hline pH & $7-9$ \\
\hline Melting point & $1550{ }^{\circ} \mathrm{C}$ \\
\hline
\end{tabular}

\subsection{Preparation of composites}

The entire amounts of NR composites made of rubber, sepiolite and other rubber additives were mixed sequentially using a Brabender (Plastograph ${ }^{\circledR}$ EC Plus, Mixer W50EHT $3 Z$, Germany). Sepiolite was varied from $0-20 \mathrm{phr}$. The compounds were then passed through a two-roll mill after dumping to remove excess heat. Next, the compounds were compression molded into certain shapes by a hydraulic hot press, depending on the curing times obtained from a movingdie rheometer (MDR) as described in the following section.

\subsection{Curing characteristics}

A moving-die rheometer (Rheoline, Mini MDR Lite (Prescott Instrument Ltd., UK) was implemented to perform the curing characteristics of the compounds, at the temperature of $150{ }^{\circ} \mathrm{C}$. The data It was used to determine the torque, scorch time $\left(\mathrm{ts}_{1}\right)$ and curing time $\left(\mathrm{tc}_{90}\right)$ according to ASTM D5289.

\subsection{Attenuated Total Reflection-Fourier Transform Infrared Spectroscopy (ATR- FTIR)}

The FTIR spectra of the NR/sepiolite composites were analyzed using a Bruker FTIR spectrometer (Tensor27) with a smart durable single bounce diamond in the ATR cell. Each spectrum was recorded in transmission mode after 32 scans per spectrum, with $4 \mathrm{~cm}^{-1}$ resolutions from 4000 to $400 \mathrm{~cm}^{-1}$.

\subsection{X-Ray Diffraction}

The XRD patterns of the samples were measured by a PHILIPS X'Pert MPD, using a CuK $\alpha$ radiation tube $(\lambda=0.154 \mathrm{~nm})$ at $40 \mathrm{kV}$ and $30 \mathrm{~mA}$ current. The diffraction pattern was scanned across $2 \theta=5-30^{\circ}$ with a step size of $0.05^{\circ}$ at $3^{\circ} / \mathrm{min}$ scan speed. The d-spacing of the layers of particles was further calculated from Bragg's equation $(\mathrm{n} \lambda=2 \mathrm{~d} \sin \theta)$, where $\lambda$ is the wavelength of the $\mathrm{X}$-ray, $\mathrm{d}$ is the interlayer distance, and $\theta$ is the angle of the incident $\mathrm{X}$-ray radiation.

\subsection{Dynamic Properties}

The dynamic properties of the NR/sepiolite composites were determined using a Rubber Process Analyzer model D-RPA 3000 (MonTech Werkstoffprüfmaschinen $\mathrm{GmbH}$, Buchen, Germany). The composite sample was cured at $150^{\circ} \mathrm{C}$ based on the curing time observed from the same RPA. Then, temperature was cooled down until $60^{\circ} \mathrm{C}$. The testing was then carried out at frequency of $10 \mathrm{~Hz}$ and strains in the range of 0.5 to $90 \%$. The raw outputs in term of storage modulus $\left(\mathrm{G}^{\prime}\right)$ and damping characteristic $(\tan \delta)$ were recorded whereby the rubber-filler interaction of the composites were monitored through the Payne effect. Payne effect can be calculated according to the equation below;

$$
\text { Payne effect }=G_{i}^{\prime}-G_{f}^{\prime}
$$

where $G_{i}^{\prime}$ is the $G^{\prime}$ at $0.5 \%$ strain and $G_{f}^{\prime}$ is the $G^{\prime}$ at $90 \%$ strain. Higher Payne effect indicates lower rubber-filler interaction.

\subsection{Measurement of tensile properties}

The vulcanizates were cut into dumbbell shapes to perform tensile properties according to ASTM D412. The test was carried out using a universal tensile testing machine (Tinius Olsen, H10KS) at a cross-head speed of $500 \mathrm{~mm} / \mathrm{min}$. The results obtained were stress at any given strain, tensile strength and elongation at break.

\subsection{Scanning Electron Microscopy}

The broken samples after tensile test was used to study the morphology of the composite. The image was captured using a scanning electron microscope (Quanta 400) to obtain information on the dispersion of the sepiolite filler in the NR matrix. The fractured samples were firstly coated with gold palladium layer to avoid electrostatic charging built while examining.

\section{Results and Discussion}

\subsection{FTIR spectrum}

Figure 2 shows the FTIR spectra in the wavenumber range of 4000-400 $\mathrm{cm}^{-1}$ for the sepiolite powder, raw NR, and NR containing 10 and $20 \mathrm{phr}$ sepiolites. The corresponding peak assignments are summarized in Table 3. For neat sepiolite powder, the absorption bands around 1662 and $1418 \mathrm{~cm}^{-1}$ are specifically assigned to the stretching vibrations of $\mathrm{O}-\mathrm{H}$ in Zeolitic and Interlayer O-H vibration. The special characteristic peaks of the sepiolite are found at around 1072,1038 and $444 \mathrm{~cm}^{-1}$ respectively, associated with stretching of $\mathrm{Si}-\mathrm{O}^{14}$. As for the raw NR, the characteristic peaks are found at around $2958 \mathrm{~cm}^{-1}, 2918 \mathrm{~cm}^{-1}$ and 2818 $\mathrm{cm}^{-1}$, indicating the $\mathrm{CH}$ stretching vibrations of carbon-carbon double bond in NR. Other important peaks are at $1662 \mathrm{~cm}^{-1}$, $1448 \mathrm{~cm}^{-1}, 1375 \mathrm{~cm}^{-1}$, and $837 \mathrm{~cm}^{-1}$, associated with the stretching vibrations of $\mathrm{C}=\mathrm{C}$ bonds, bending vibrations of $\mathrm{CH}_{2}$ and $\mathrm{CH}_{3}$ groups, and out of plane deformations of $=\mathrm{C}-\mathrm{H}$ groups, respectively. Upon inclusion of sepiolite and further increasing in the sepiolite loadings have increased the peak intensities of Si-O vibration, corresponding to the content of sepiolite in the NR matrix. Most peaks observed were in good agreement to the literatures ${ }^{14,15}$.

\section{$3.2 X$-ray Diffraction}

Figure 3 shows the XRD pattern of raw sepiolite and NR composites containing 5, 15 and 20 phr of sepiolite. The $2 \theta$ values of diffraction peak and their relative d-spacing are discussed. The peak at $10.4^{\circ}$ of pure sepiolite powder 


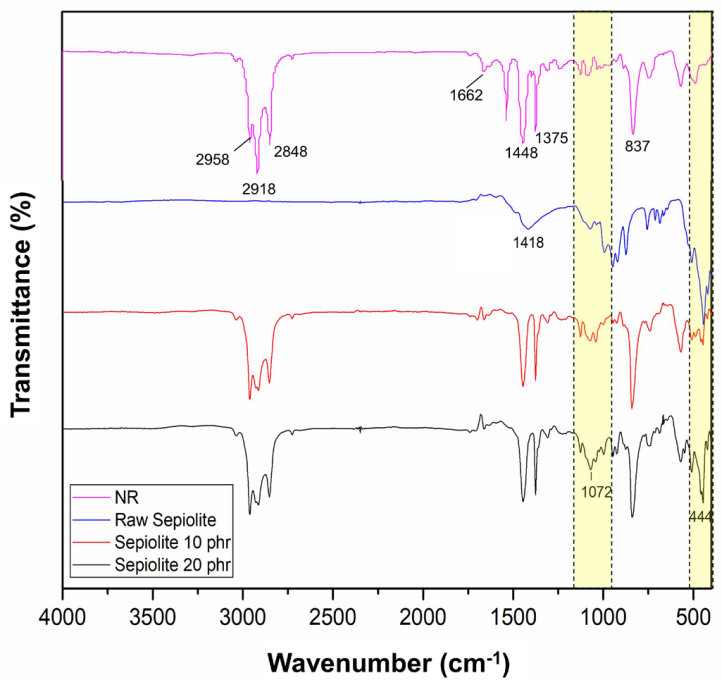

Figure 2. FTIR spectrum of raw sepiolite, NR and sepiloite filled NR composites.

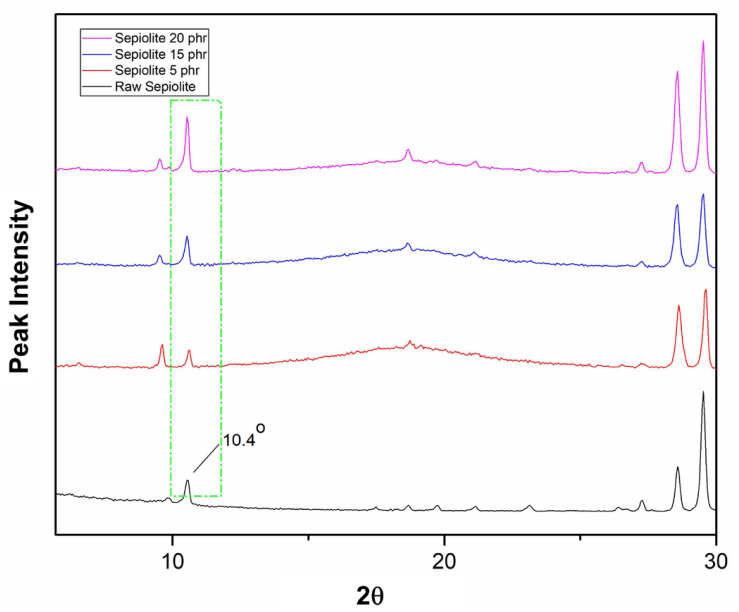

Figure 3. XRD patterns of raw sepiolite and sepiloite filled NR composites.

corresponded to $\mathrm{d}_{110}$ basal spacing which $\mathrm{d}$ is $8.38 \mathrm{~A}^{\circ}$. This indicates that the sepiolite has original distance between layers of $8.38 \mathrm{~A}^{\circ}$ and was mainly in dehydrated form. The peak observed was dissimilar to the literatures ${ }^{16-18}$, where it was mostly found at $2 \theta$ values of $7.3-8.5^{\circ}$, corresponding to the to $\mathrm{d}_{110}$ basal spacing. However, Singh et al. ${ }^{19}$, has reported that the shifting of such peak may be presented if the sepiolite is heated at the temperature over $550^{\circ} \mathrm{C}$. This may be possible as the sepiolite obtained was heated prior during mining process. Apart from that, the peak intensity at $10.4^{\circ}$ was more intense as increased the addition of sepiolite. This is associated to the higher amount of sepiolite which controls the crystal peak of sepiolite ${ }^{19,20}$.

\subsection{Curing characteristics}

Figure 4 illustrates the curing curves of the sepiolite filled NR composites whereas the raw data obtained from the curing curves are also listed in Table 4. Minimum torque

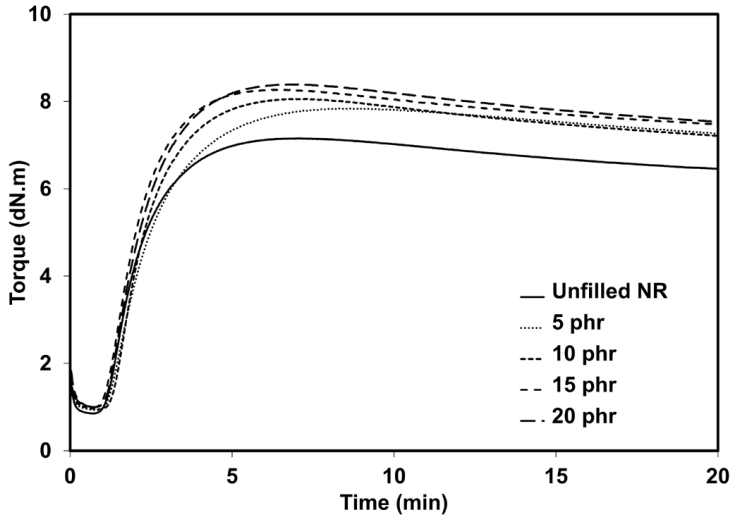

Figure 4. Curing curves of unfilled and sepiolite filled NR composites.

$\left(\mathrm{M}_{\mathrm{L}}\right)$ is an indirect indication of compound's viscosity of rubber and the maximum torque $\left(\mathrm{M}_{\mathrm{H}}\right)$ refers to the stiffness or shear modulus of the completely cured rubber at the tested temperature. The $\mathrm{M}_{\mathrm{L}}$ and $\mathrm{M}_{\mathrm{H}}$ exhibited an increment trend over the sepiolite content. Sepiolite is similar to other types of clay minerals which is naturally rigid form, thus, increasing the sepiolite content has risen undeformed component in the rubber compounds. This behavior restricts the movement of the molecular chain while testing, leading to an increment of the compound's viscosity and stiffness of the composites ${ }^{20}$. Similar trend was also observed for the torque difference $\left(\mathrm{M}_{\mathrm{H}}-\mathrm{M}_{\mathrm{L}}\right)$, that indicates the difference between shear modulus of cured and uncured compounds recorded at top and bottom points of the curing curve. The $\mathrm{M}_{\mathrm{H}}-\mathrm{M}_{\mathrm{L}}$ value also relates to the stiffness in the composite. Based on the results obtained, it can be said that the addition of sepiolite has increased the rigidity which can reduce the fraction of deformable rubber in the compounds.

Another key parameter to consider while compounding the rubber is the time consuming during the vulcanizing process of the rubber compound. Here, scorch time $\left(\mathrm{ts}_{1}\right)$ and curing time $\left(\mathrm{tc}_{90}\right)$ are used to evaluated. These two values are measures of the time spent to initiate and complete the vulcanization process. As seen in Table 4 , the ts ${ }_{1}$ and $\mathrm{tc}_{90}$ slowly decreased over the sepiolite content. Short curing time is extremely beneficial for production due to the increment of the production rate. The decreased of these values can be associated to the physical and chemical parameters of sepiolite itself e.g., moisture content, metal oxide content and the surface area. Especially, the magnesium oxide $(\mathrm{MgO})$ content in the sepiolite itself, this can be clearly seen from the chemical structure of sepiolite shown in Figure 1. As widely known that $\mathrm{MgO}$ is practically used as an activator for the rubber compounds ${ }^{21}$, the role of $\mathrm{MgO}$ is to act as a cation which then activate the crosslinking process at the diene backbone of the rubber. Despite the $\mathrm{MgO}$ contained in the sepiolite, other type of metal oxide, known as $\mathrm{ZnO}$ was also added in the formulation. This has brought to provide high efficiency of activating process during the vulcanization. Hence, the $\mathrm{ts}_{1}$ and $\mathrm{tc}_{90}$ were shortened by the addition of sepiolite. The participation of the $\mathrm{MgO}$ on cure behavior can be later confirmed by increasing value of cure rate index (CRI) which suggested that the curing reaction was faster with increased addition of sepiolite filler. 
Table 3. Wavenumbers and their corresponding assignments of FTIR spectra observed in this study ${ }^{12,13}$.

\begin{tabular}{|c|c|c|}
\hline Materials & Wavenumbers $\left(\mathrm{cm}^{-1}\right)$ & Assignments \\
\hline \multirow{4}{*}{ Sepiolite } & 1662 & $\mathrm{O}-\mathrm{H}$ stretching vibrations in Zeolitic \\
\hline & 1418 & Interlayer $\mathrm{O}-\mathrm{H}$ vibration \\
\hline & $10,721,038$ & Skeleton Si-O stretching vibration (Si-O-Si, O-Si-O) \\
\hline & 444 & $\mathrm{Si}-\mathrm{O}-\mathrm{Si}$ and $\mathrm{Si}-\mathrm{O}$ deformation vibrations \\
\hline \multirow{7}{*}{ NR } & 2958 & $-\mathrm{C}-\mathrm{H}$ stretching vibration of carbon-carbon double bond \\
\hline & 2918 & $\mathrm{CH}_{2}$ stretching vibration of $-\mathrm{C}=\mathrm{C}-$ \\
\hline & 2848 & $\mathrm{CH}$ stretching vibration of $-\mathrm{C}=\mathrm{C}-$ \\
\hline & 1662 & $\mathrm{C}=\mathrm{C}$ stretching vibration \\
\hline & 1448 & Bending vibration of $\mathrm{C}-\mathrm{H}$ \\
\hline & 1375 & Scissoring vibration of $\mathrm{CH}_{3}$ \\
\hline & 837 & Out-of-plane bending vibration of $\mathrm{C}-\mathrm{H}$ in the $-\mathrm{CH}=\mathrm{CH}-$ group \\
\hline
\end{tabular}

Table 4. Curing characteristics of the unfilled and sepiolite filled NR composites.

\begin{tabular}{|c|c|c|c|c|c|c|}
\hline $\begin{array}{c}\text { Sepiolite } \\
\text { content (phr) }\end{array}$ & $M_{L}(d N . m)$ & $M_{H}(d N . m)$ & $M_{H}-M_{L}$ (dN.m) & $\mathrm{ts}_{1}(\mathrm{~min})$ & $\mathrm{tc}_{90}(\min )$ & CRI $\left(\min ^{-1}\right)$ \\
\hline 0 & 0.96 & 7.03 & 6.07 & 1.72 & 4.58 & 34.97 \\
\hline 5 & 1.03 & 7.07 & 6.04 & 1.44 & 3.97 & 39.53 \\
\hline 10 & 1.09 & 7.35 & 6.26 & 1.39 & 3.85 & 40.65 \\
\hline 15 & 1.1 & 8.1 & 7 & 1.34 & 3.77 & 41.15 \\
\hline 20 & 1.16 & 8.84 & 7.68 & 1.29 & 3.58 & 43.67 \\
\hline
\end{tabular}

\subsection{Payne effect}

Dynamic properties of the composites were carried out using Rubber Process Analyzer. This is to investigate the storage modulus, Payne effect and the damping characteristics of the composites. Figure 5 illustrates the storage modulus of the composites. It exhibits that the storage modulus of gum NR showed constant values at low strain region but slightly decrease when the strain is higher than $50 \%$. This is the common phenomenon happens to the viscoelastic material due to the molecular stability of the rubber. Furthermore, all sepiolite filled NR composites shows a behavior called nonlinear viscoelastic behavior where the storage modulus increased over the sepiolite content. The filler network formation may be responsible to the case observed, which strongly relates to the self-aggregation tendency or an agglomeration. Also, the storage modulus dropped at high shear strain and kept decreasing till a minimum value. This is simply attributed to the breakdown of filler-filler networks.

In addition to that, the Payne effects of all composites were also estimated from the differences between the storage modulus at low strain and high strain amplitudes (see the Table embedded in the Figure 5). The level of $G^{\prime}{ }_{i}-G^{\prime}{ }_{f}$ was found to be $68.83,127.97,128.02,163.21$ and $198.06 \mathrm{kPa}$ for the unfilled NR and filled NR at 5-20 phr respectively. Increasing these values is attributed to formation of filler's network and indicates a high filler-filler interaction ${ }^{5}$. A drastic increment of Payne effect was observed particularly at $20 \mathrm{phr}$ of sepiolite which is attributed to the large agglomeration of sepiolite in the composites. The results from Payne effect is in good agreement to the tensile strength observed especially at $20 \mathrm{phr}$ of sepiolite content.

Dependence of damping characteristic $(\tan \delta)$ as functions of strain is shown in Figure 6. It is obvious that the composites exhibited higher damping characteristics over the addition of sepiolite in the composite, indicating a considerable decrease in the degree of mobility and hence

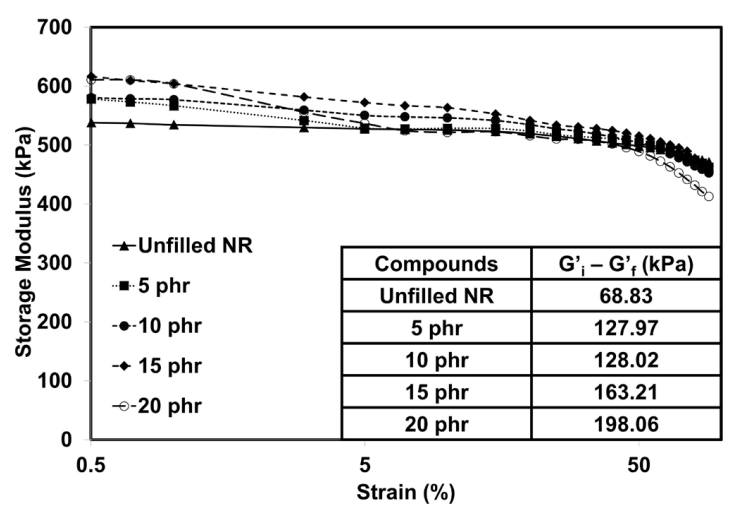

Figure 5. Storage modulus and Payne effect of unfilled and sepiolite filled NR composites.

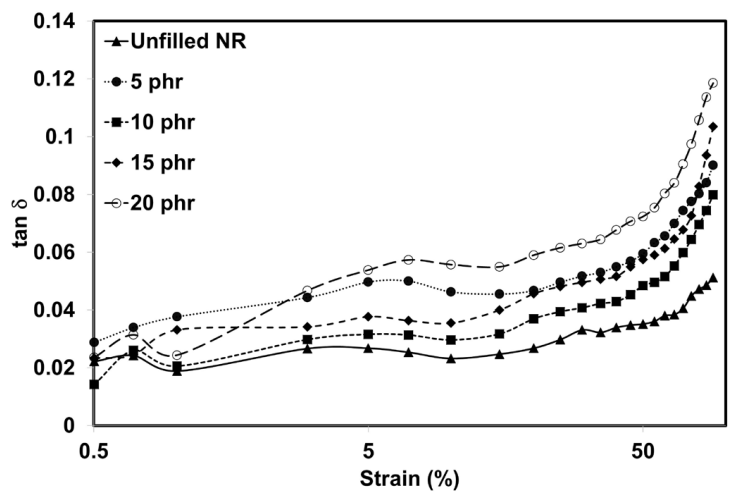

Figure 6. Damping factor or $\tan \delta$ of unfilled and sepiolite filled NR composites.

increasing the damping behavior. This is simply due to the dilution effect due to the replacement of sepiolite over the elastic rubber ${ }^{22,23}$. 


\subsection{Tensile properties}

Figure 7 shows the stress-strain curves of sepiolite filled NR composites. Typical strain-induced crystallization of unfilled NR and of NR containing 5-20 phr of sepiolite is seen in the stress-strain curves. The stress and strain values appear to differ between the unfilled and filled NR. From the stress-strain curves, it is possible to estimate the change point of the strain for each of the samples. Clearly, the strain at the onset of the stress upturn for the NR containing sepiolite is much lower than that of the unfilled NR, and the onset strain decreases with increasing sepiolite loading. This observation indicates that the addition of sepiolite affects the stress-strain behavior of NR and lowers the strain at the onset of the stress upturn. Further, the area underneath the stress-strain curve was examined to indicate the toughness of a material ${ }^{24}$. The largest area underneath the curve corresponds to the greatest toughness. The sepiolite filled NR composites showed a greater area underneath the stress-strain curve than the unfilled NR, and, therefore, greater toughness.

To focus more in details, the results obtained from stressstrain curves were extracted in terms of stress at 100\% (M100) and 300\% (M300) strains, tensile strength and elongation at break. These values are listed in Table 5. It exhibits that sepiolite has greatly affected the tensile strength. The highest tensile strength obtained at $15 \mathrm{phr}$ sepiolite contents was about $30 \%$ higher than the neat NR. The tensile strength values however decreased after $15 \mathrm{phr}$ of the sepiolite content. The unique characteristics and morphology of sepiolite play very important role in reinforcing the NR matrix. A needle-like shape of sepiolite holds certain probability to have an efficient contact to the rubber. This has brought

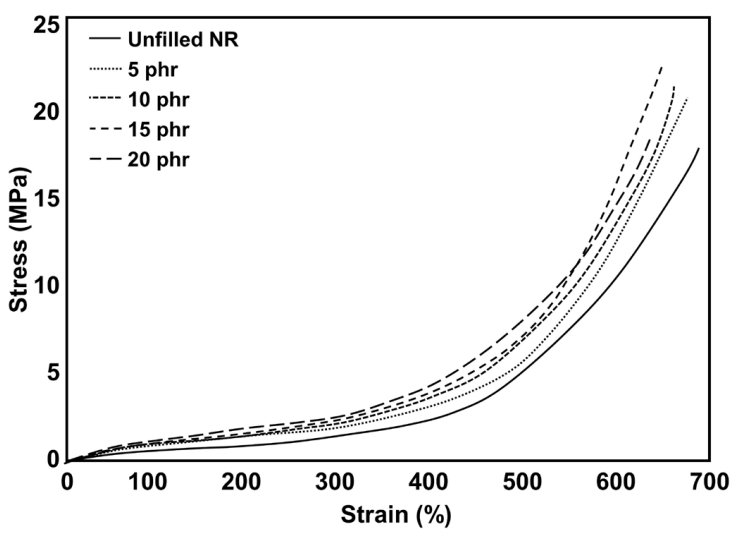

Figure 7. Stress-strain curves of unfilled and sepiolite filled NR composites. to an adequate surface area to be able to interact with the rubber and diminish filler-filler distance. Surface area is an important factor in the composite structure, the larger the surface area of the filler, higher possibility of contact takes place $^{25,26}$, giving efficient stress-transfer from one another The decrease in tensile strength with sepiolite content above $15 \mathrm{phr}$ is simply contributed to the agglomeration of filler or so-called filler-filler interaction ${ }^{20}$. When high amount of sepiolite was added, the sepiolite itself tend to interact themselves due to the strong physical adsorption among them. In this case, the silanol groups available at the outer surface of sepiolite. This has created the area of agglomeration in the composite. This enabled to act as barrier to the movement of rubber chains and created catastrophic failure under stress ${ }^{27}$ which has caused a reduction in tensile strength of the composite.

As for the tensile modulus of the sepiolite filled NR composites, it was observed that the M100 and M300 increased slightly over the sepiolite content. As sepiolite particles incorporated into the rubber, the flexibility of the rubber is reduced due to the dilution effect ${ }^{28}$, resulting in stiffer vulcanizate. This can be clearly seen from the reduction of elongation at break observed previously. Such finding is responsible to the fact that the sepiolite is naturally hard phase, which unable to deform. As a result, the internal strain of the rubber matrix is superior than the external counterpart yielding a strain independent contribution to the modulus ${ }^{29}$. This result correlates to the $\mathrm{M}_{\mathrm{H}}$ observed in the previous section.

\subsection{Tensile fractured surfaces}

Figure 8 illustrates the SEM micrographs of tensile fractured surfaces of sepiolite filled NR composites at $100 \times, 1,500 \times$ and 5,000 $\times$ magnifications. At lower amount of sepiolite (see S5), less amount of particulates was seen because there was still small amount of sepiolite added. However, such dispersion is enough to assist the stress transfer to each other. Rougher surface and better dispersion of sepiolite were then observed when sepiolite was incorporated at $15 \mathrm{phr}$ (see S15). The observed roughness and frequency of tearing indicates that high energy is required to break the sample. A gradual increase in the surface roughness over the sepiolite content is simply responsible to the tensile results obtained. Moreover, this behaviour is not seen when sepiolite was added above $15 \mathrm{phr}$ (see S20). The agglomeration of sepiolite is also seen together with detachment of sepiolite, due to the strong filler-filler interaction. Therefore, less breaking energy is involved to the tensile sample in this case. Other works have reported similar observations especially on the changes of micro-fractured surfaces or micro-defects of the

Table 5. Tensile properties of the unfilled and sepiolite filled NR composites.

\begin{tabular}{|c|c|c|c|c|}
\hline \multirow{2}{*}{ Sepiolite content (phr) } & M100 & M300 & \multirow{2}{*}{ Tensile Strength (MPa) } & \multirow{2}{*}{$\begin{array}{c}\text { Elongation at Break } \\
(\%)\end{array}$} \\
\hline & (MPa) & (MPa) & & \\
\hline 0 & $0.74 \pm 0.05$ & $1.78 \pm 0.16$ & $17.94 \pm 0.79$ & $698 \pm 7.27$ \\
\hline 5 & $0.80 \pm 0.07$ & $1.95 \pm 0.15$ & $20.63 \pm 0.95$ & $682 \pm 7.01$ \\
\hline 10 & $0.86 \pm 0.04$ & $2.05 \pm 0.14$ & $21.33 \pm 0.88$ & $657 \pm 10.12$ \\
\hline 15 & $0.93 \pm 0.04$ & $2.08 \pm 0.11$ & $22.91 \pm 0.81$ & $651 \pm 10.99$ \\
\hline 20 & $1.03 \pm 0.06$ & $2.26 \pm 0.14$ & $18.47 \pm 0.59$ & $636 \pm 10.65$ \\
\hline
\end{tabular}




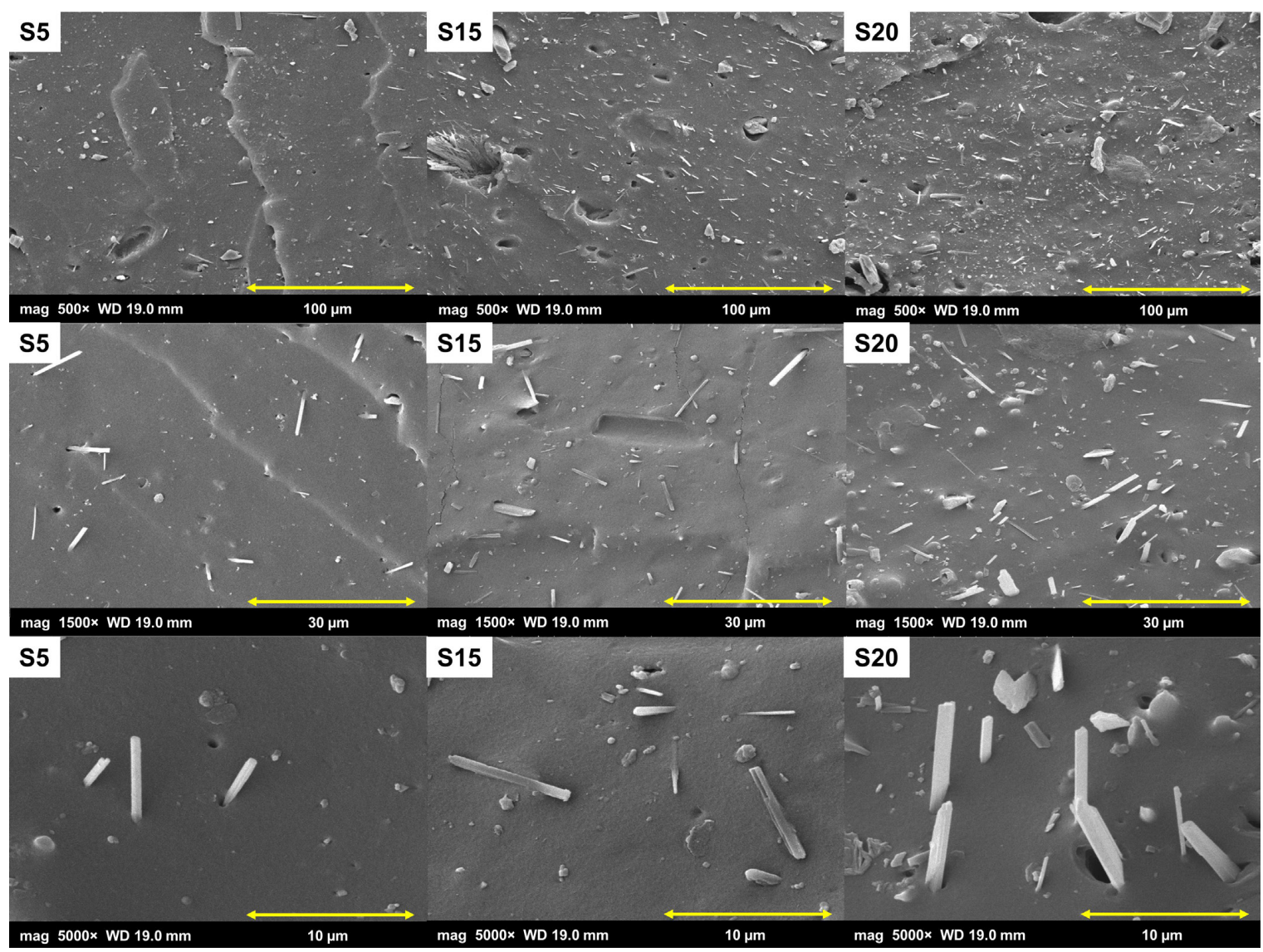

Figure 8. SEM images obtained from tensile fractured surfaces of unfilled and sepiolite filled NR composites at 500×, 1,500× and 5,000× magnifications.

rubber samples after the incorporation of fillers in natural rubber composites ${ }^{30-32}$.

\section{Conclusion}

This work aimed to utilize the sepiolite as alternative filler for NR matrix. Sepiolite has very unique characteristics especially from the needle-like and elongated shapes. Based on the functionality observation of sepiolite, the chemical structure of sepiolite is almost similar to clay family. However, the morphology of sepiolite is somewhat interesting, it enabled to disperse well in the NR matrix and provided very good properties to the composites. Such reinforcement can be viewed from an increment of tensile strength over the sepiolite content together with the supporting evidence obtained from SEM images. Due to the presence of $\mathrm{MgO}$ available in sepiolite, it played very important role in the curing process of the composites. $\mathrm{MgO}$ could act as curing activator for vulcanization, resulting to reduce the vulcanizing time of the composites. In summary, the sepiolite has shown to be a filler of choice for preparing rubber composites where the loadings of $15 \mathrm{phr}$ is highly suggested to be used for NR due to the overall satisfactory properties. To some extent, sepiolite could also replace the addition of white fillers such as silica, clay and calcium carbonate without requiring the addition of silane coupling agent which is considered the complicated and costly methods.

\section{References}

1. Fischer H. Polymer nanocomposites: from fundamental research to specific applications. Mater Sci Eng C. 2003;23(6-8):763-72. http://dx.doi.org/10.1016/j.msec.2003.09.148.

2. Roy K, Debnath SC, Bansod ND, Pongwisuthiruchte A, Wasanapiarnpong T, Potiyaraj P. Possible use of gypsum waste from ceramics industry as semi-reinforcing filler in epoxidized natural rubber composites. J Mater Cycles Waste Manag. 2020;22(1):285-94. http://dx.doi.org/10.1007/s10163019-00939-w.

3. Delgado E, Espitia A, Aperador W. Comparative evaluation of Clusia multiflora wood flour, against mineral fillers, as reinforcement in SBR rubber composites. Iran Polym J. 2020;29(1):13-23. http://dx.doi.org/10.1007/s13726-019-007686.

4. Ray SS, Okamoto M. Polymer/layered silicate nanocomposites: a review from preparation to processing. Prog Polym Sci. 2003;28(11):1539-641. http://dx.doi.org/10.1016/j. progpolymsci.2003.08.002.

5. Rooj S, Das A, Thakur V, Mahaling RN, Bhowmick AK, Heinrich G. Preparation and properties of natural nanocomposites based on natural rubber and naturally occurring halloysite nanotubes. Mater Des. 2010;31(4):2151-6. http://dx.doi.org/10.1016/j. matdes.2009.11.009.

6. Nabil H, Ismail H, Azura A. Recycled polyethylene terephthalate filled natural rubber compounds: effects of filler loading and types of matrix. J Elastomers Plast. 2011;43(5):429-49. http:// dx.doi.org/10.1177/0095244311405503. 
7. Santaren J, Sanz J, Ruiz-Hitzky E. Structural fluorine in sepiolite. Clays Clay Miner. 1990;38(1):63-8. http://dx.doi.org/10.1346/ CCMN.1990.0380109.

8. Alves L, Ferraz E, Santarén J, Rasteiro MG, Gamelas JA. Improving Colloidal Stability of Sepiolite Suspensions: Effect of the Mechanical Disperser and Chemical Dispersant. Minerals. 2020;10:779. https://doi.org/10.3390/min10090779.

9. Hayeemasae N, Ismail H. Reinforcement of epoxidized natural rubber through the addition of sepiolite. Polym Compos. 2019;40(3):924-31. http://dx.doi.org/10.1002/pc.24762.

10. Hernández LG, Rueda LI, Díaz AR. Effect of mineral filler sepiolite on sulphur-free thiuram vulcanization of natural rubber. Angew Makromol Chem. 1982;104(1):189-201. http://dx.doi. org/10.1002/apmc.1982.051040116.

11. Bhattacharya M, Maiti M, Bhowmick AK. Influence of different nanofillers and their dispersion methods on the properties of natural rubber nanocomposites. Rubber Chem Technol. 2008;81(5):782-808. http://dx.doi.org/10.5254/1.3548232.

12. Alkan M, Tekin G, Namli H. FTIR and zeta potential measurements of sepiolite treated with some organosilanes. Microporous Mesoporous Mater. 2005;84(1-3):75-83. http:// dx.doi.org/10.1016/j.micromeso.2005.05.016.

13. Chen D, Shao H, Yao W, Huang B. Fourier transform infrared spectral analysis of polyisoprene of a different microstructure. Int J Polym Sci. 2013;2013:937284. http:// dx.doi.org/10.1155/2013/937284.

14. Frost RL, Locos OB, Ruan H, Kloprogge JT. Near-infrared and mid-infrared spectroscopic study of sepiolites and palygorskites. Vib Spectrosc. 2001;27(1):1-13. http://dx.doi.org/10.1016/ S0924-2031(01)00110-2.

15. Hepburn C, Vale P, Brown A, Simms NJ, McAdam EJ. Development of on-line FTIR spectroscopy for siloxane detection in biogas to enhance carbon contactor management. Talanta. 2015;141:12836. http://dx.doi.org/10.1016/j.talanta.2015.03.063.

16. Bektaş N, Ağım BA, Kara S. Kinetic and equilibrium studies in removing lead ions from aqueous solutions by natural sepiolite. J Hazard Mater. 2004;112(1-2):115-22. http://dx.doi. org/10.1016/j.jhazmat.2004.04.015.

17. Chen H, Zheng M, Sun H, Jia Q. Characterization and properties of sepiolite/polyurethane nanocomposites. Mater Sci Eng A. 2007;445-446:725-30. http://dx.doi.org/10.1016/j. msea.2006.10.008.

18. Tartaglione G, Tabuani D, Camino G. Thermal and morphological characterisation of organically modified sepiolite. Microporous Mesoporous Mater. 2008;107(1-2):161-8. http://dx.doi. org/10.1016/j.micromeso.2007.04.020

19. Singh VP, K.K V, Sharma S, Kapur GS, Choudhary V. Polyethylene/sepiolite clay nanocomposites: effect of clay content, compatibilizer polarity, and molar mass on viscoelastic and dynamic mechanical properties. J Appl Polym Sci. 2017:134(33):45197. http://dx.doi.org/10.1002/app.45197.

20. Torró-Palau A, Fernández-García JC, Orgilés-Barceló AC, Pastor-Blas MM, Martín-Martínez J. Structural modification of sepiolite (natural magnesium silicate) by thermal treatment: effect on the properties of polyurethane adhesives. Int J Adhes Adhes. 1997;17(2):111-9. http://dx.doi.org/10.1016/S01437496(96)00039-5

21. Mittal V, Kim JK, Pal K. Recent advances in elastomeric nanocomposites. Berlin: Springer; 2011

22. Akiba M, Hashim A. Vulcanization and crosslinking in elastomers. Prog Polym Sci. 1997;22(3):475-521. http://dx.doi.org/10.1016/ S0079-6700(96)00015-9.

23. Sengloyluan K, Sahakaro K, Dierkes WK, Noordermeer JWM. Silica-reinforced tire tread compounds compatibilized by using epoxidized natural rubber. Eur Polym J. 2014;51:69-79. http:// dx.doi.org/10.1016/j.eurpolymj.2013.12.010.

24. Cataldo F. Preparation of silica-based rubber compounds without the use of a silane coupling agent through the use of epoxidized natural rubber. Macromol Mater Eng. 2002;287(5):348-52. http:// dx.doi.org/10.1002/1439-2054(20020501)287:5<348::AIDMAME348>3.0.CO;2-1.

25. Hayeemasae N, Sensem Z, Sahakaro K, Ismail H. Maleated natural rubber/halloysite nanotubes composites. Processes. 2020;8(3):286. http://dx.doi.org/10.3390/pr8030286.

26. Fröhlich J, Niedermeier W, Luginsland H-D. The effect of fillerfiller and filler-elastomer interaction on rubber reinforcement. Compos, Part A Appl Sci Manuf. 2005;36(4):449-60. http:// dx.doi.org/10.1016/j.compositesa.2004.10.004.

27. Ishak Z, Aminullah A, Ismail H, Rozman H. Effect of silanebased coupling agents and acrylic acid based compatibilizers on mechanical properties of oil palm empty fruit bunch filled high-density polyethylene composites. J Appl Polym Sci. 1998;68(13):2189-203. http://dx.doi.org/10.1002/(SICI)10974628(19980627)68:13<2189::AID-APP16>3.0.CO;2-V.

28. Pasbakhsh P, Ismail H, Fauzi MA, Bakar AA. Influence of maleic anhydride grafted ethylene propylene diene monomer (MAH-g-EPDM) on the properties of EPDM nanocomposites reinforced by halloysite nanotubes. Polym Test. 2009;28(5):54859. http://dx.doi.org/10.1016/j.polymertesting.2009.04.004.

29. De D, De D, Adhikari B. The effect of grass fiber filler on curing characteristics and mechanical properties of natural rubber. Polym Adv Technol. 2004;15(12):708-15. http://dx.doi. org/10.1002/pat.530.

30. Narongthong J, Wießner S, Hait S, Sirisinha C, Stöckelhuber KW. Strain-rate independent small-strain-sensor: enhanced responsiveness of carbon black filled conductive rubber composites at slow deformation by using an ionic liquid. Compos Sci Technol. 2020;188:107972. http://dx.doi.org/10.1016/j. compscitech.2019.107972.

31. Jordhamo G, Manson J, Sperling L. Phase continuity and inversion in polymer blends and simultaneous interpenetrating networks. Polym Eng Sci. 1986;26(8):517-24. http://dx.doi. org/10.1002/pen.760260802.

32. Mathialagan M, Ismail H. Optimization and effect of 3aminopropyltriethoxysilane content on the properties of bentonitefilled ethylene propylene diene monomer composites. Polym Compos. 2012;33(11):1993-2000. http://dx.doi.org/10.1002/ pc. 22340 . 